\title{
Uma Avaliação das Equipes de Projeto em um Momento Pré-Avaliação Oficial de um Programa de Melhoria de Processo de Software visando o CMMI nível $2^{1}$
}

\author{
Luciane Soares Rabello Moreira ${ }^{1}$, Vanessa Costa Samrsla ${ }^{1}$, Michael da Costa Móra ${ }^{2}$, \\ Rafael Prikladnicki ${ }^{2}$, Rosane Bossle ${ }^{1}$, Reginaldo Back ${ }^{1}$ \\ ${ }^{1}$ Tlantic Sistemas de Informação \\ ${ }^{2}$ Pontifícia Universidade Católica do Rio Grande do Sul - PUCRS \\ Av Ipiranga 6681 - 90619.900 - Porto Alegre - RS \\ \{michael, rafael\}@inf.pucrs.br \\ \{lsoares, vanessac, rbossle, rback\}@tlantic.com.br
}

\begin{abstract}
Resumo. Geralmente, a participação das equipes de projetos em programas de melhoria da qualidade está centrada na definição de processos, ajuda na validação, podendo ainda ministrar treinamentos ou ainda participar do SEPG da empresa. Mas ao mesmo tempo, sabe-se que existe um desafio entre o tempo de dedicação para um projeto como este e as atividades rotineiras de projetos de software. Além disso, a necessidade de preparação das equipes de projeto para uma avaliação oficial sempre é considerado um fator crítico. Desta forma, o objetivo deste artigo é relatar uma avaliação realizada com equipes de projeto selecionados para uma avaliação oficial no modelo CMMI visando o nível 2. Ao final, lições aprendidas são identificadas.
\end{abstract}

Abstract. When organizations creates a software engineering process improvement program, it usually establises a team that is responsible for leading the improvement effort, with the cooperation of the resources of project teams. These teams help define and validate the processes, as well as may help training other project teams. Coordinating this dedication to the improvement activities while retaining responsabilities in the software projects is challaneging for team members. Still, it is important to consider the need to prepare the teams that will take part in the formal evaluation. Therefore, the purpose of this paper is to report the evaluation of project teams selected to be part of the formal evaluation sessions in order to achieve CMMI level 2.

\section{Introduçao}

Nos últimos anos, as organizações de desenvolvimento de software têm aumentado sua percepção em relação aos problemas que tipicamente ocorrem neste contexto. Software com defeitos, prazos e orçamentos não cumpridos e insatisfação de clientes têm se tornado bastante comum (Sommerville, 2003). Segundo Agnol (Agnol, 2004), sabe-se que desde a década de 1970 existe um consenso na comunidade de Engenharia de Software de que estes problemas estão, em grande parte, relacionados ao fato de que o desenvolvimento de software é muitas vezes realizado através de métodos improvisados. Desta forma o sucesso 
depende muito mais do talento individual dos desenvolvedores do que da formação acompanhada de métodos formais que dirijam suas atividades. Além disso, muito mais do que ter como necessidade a melhoria da qualidade do produto final, resultante do processo de desenvolvimento de software, as empresas têm se preocupado em melhorar o próprio processo de desenvolvimento como forma de buscar a garantia da qualidade.

Neste contexto, surgem modelos de qualidade, como, por exemplo, o Capability Maturity Model (CMM) e o MR mps, usados pelas organizações tanto como guias para definir seus processos de software e a maturidade dos mesmos, quanto para orientar um trabalho de melhoria destes processos. O CMM para a área de desenvolvimento de software foi criado em 1993, através do modelo SW-CMM. Ele foi desenvolvido através de observações das melhores práticas nas organizações de software e reflete uma coletânea de experiências e expectativas de muitas delas [JAL99]. Este modelo foi utilizado durante 10 anos, quando deu lugar ao sucessor, o CMMI (Capability Maturity Model Integration).

Hoje em dia percebe-se que muitas organizações têm investido em programas de melhoria de processo de software. Muitas delas têm como base o modelo CMMI. E ao ingressar em um programa de melhoria de processo, a organização passa e ter como uma das atividades essenciais, a necessidade de investir no treinamento da sua equipe, de forma a capacitá-la e torná-la apta a responder às necessidades que um projeto como este impõe. Desta forma, o objetivo deste artigo é relatar uma avaliação realizada com equipes de cinco projetos selecionados para uma avaliação formal de nível 2 do modelo CMMI, apresentando resultados do momento pré-avaliação e da percepção dos integrantes das equipes em relação a diversos fatores, entre eles: o que foi realizado até aquele momento no programa de melhoria de processo; a percepção em relação ao momento da entrevista com a equipe de avaliação; os riscos da avaliação oficial e da entrevista; a percepção de futuro após a avaliação, sendo ela positiva ou negativa.

O artigo está dividido em 6 seções. A seção dois apresenta a base conceitual envolvida. A seção 3 descreve as atividades realizadas com as equipes de projetos e os resultados encontrados. Na seção 4 são apresentadas as lições aprendidas. Por fim, a seção 5 aborda as considerações finais e a seção 6 apresenta a bibliografia utilizada.

\section{Programas de Melhoria de Processo de Software e o CMMI}

Programas de melhoria de processo de software têm sido criados nas empresas para auxiliar na implantação de modelos de qualidade amplamente difundidos na indústria. Geralmente, estes programas são acompanhados de um planejamento rigoroso e da definição clara dos objetivos a serem alcançados e das etapas necessárias para o alcance destes objetivos.

Do ponto de vista dos modelos de qualidade utilizados em programas como este, o CMMI aparece como um framework que possui os elementos necessários para tornar um processo de desenvolvimento de software mais eficiente e controlado (Bartié, 2002), e tem sido bastante utilizado nos dias atuais. O CMMI foi construído para integrar os diferentes modelos criados a partir do sucesso alcançado pelo CMM para software. Além disso, o CMMI introduziu duas representações para apresentar seu conteúdo. O programa de melhoria relatado neste artigo adotou a representação por estágios, pois ela provia uma sequiência comprovada de melhorias, iniciando com práticas básicas e evoluindo através de um caminho pré-definido de níveis sucessivos. 


\section{Avaliação das Equipes de Projeto em um Momento de Pré-Avaliação Oficial}

Baseando-se na leitura do contexto organizacional, bem como nas equipes que faziam parte deste ambiente, levantou-se a necessidade de se trabalhar os aspectos não técnicos envolvidos no programa de melhoria da organização, visando identificar e minimizar possíveis riscos antes da avaliação oficial que seria realizada. Todas as iniciativas realizadas durante os 10 meses do projeto de implantação do CMMI nível 2 na organização, focadas no conhecimento técnico do processo, já estavam concluídas, pois a cultura de processo já estava visivelmente instalada na atmosfera da instituição. Notava-se, portanto, uma oportunidade entre o nível de preparo técnico e psicológico dos envolvidos no contexto da avaliação. Entre algumas características observadas, destacavam-se: ansiedade elevada, disparidade entre a situação imaginada do momento da avaliação versus a situação real, auto-exigência demasiada, falta de informação sobre o manejo comportamental no decorrer da entrevista, entre outros aspectos nos evidenciavam este fator.

Desta forma, a partir da realidade descrita, percebeu-se um espaço muito propício para serem trabalhados conteúdos referentes à percepção dos grupos avaliados sobre o momento ansiogênico em que a organização estava inserida. Este trabalho foi pensado de forma que pudesse agregar algum valor para as equipes de projeto, em um momento que antecedeu a avaliação oficial de nível 2, avaliação esta que envolveria tanto a verificação de documentação de projetos quanto a realização de entrevistas individuais. Desta forma, a seguir serão relatados a atividade realizada e os resultados encontrados, que culminou no reconhecimento da organização com sendo nível dois de maturidade de acordo com as práticas sugeridas pelo modelo CMMI. É importante ainda destacar que a atividade relatada teve um apoio incondicional do departamento de recursos humanos da empresa, que vislumbrou a oportunidade de trabalho e de um complemento fundamental referente ao preparo das equipes para as atividades envolvidas na avaliação.

\subsection{A Organização}

A Tlantic S.I. é uma empresa do Grupo SONAE que, derivada de um departamento de tecnologia da informação na sede da SONAE Distribuição Brasil (rede de hipermercados), instalou-se no Tecnopuc (Parque Tecnológico da PUCRS) com o objetivo de buscar uma sinergia entre empresa e universidade. $\mathrm{O}$ foco do negócio está em fornecer soluções na área de TI para empresas do grupo. Atualmente a organização possui 153 colaboradores entre funcionários diretos, estagiários e terceiros. Fundada em Janeiro de 2004, a Tlantic S.I. lançou-se com foco em qualidade. Estipulou como meta organizacional ser reconhecida como uma organização CMMI nível 2 no período de 10 meses (Abril de 2004 a Janeiro de 2005), obtendo êxito neste objetivo.

A estrutura interna da empresa organiza-se em: área estratégica (Direção), área administrativa/financeira, área comercial, gestão de pessoas e área de operações. Dentro da área de operações derivam-se centros de competência que possuem equipes próprias. Os centros de competências são baseados em tecnologias específicas, permitindo a fabricação de softwares focados nas tecnologias utilizadas em cada projeto. Cada equipe de projeto possui sua respectiva hierarquia, definida da seguinte forma: um gerente de sistemas que coordena o centro de competência onde o projeto está vinculado, um gestor de projetos, analistas de sistemas, programadores, testadores, entre outros. A cada projeto estas equipes são realocadas conforme a demanda apresentada pela empresa. 


\subsection{Descrição da Atividade Realizada}

Tendo como objetivo principal a complementação da preparação das equipes dos projetos selecionados para a avaliação oficial de nível 2 no CMMI, foi realizado um levantamento das necessidades percebidas nos projetos. Logo a seguir, foi elaborado um plano de atividades não técnicas no intuito de trabalhar pontos fundamentais para o bom desempenho das equipes durante a avaliação. Objetivando refletir a percepção das equipes de projetos à luz da representatividade da avaliação formal dentro de uma perspectiva organizacional focada em atingir a excelência em qualidade de software, elaborou-se então uma série de atividades que, alinhadas com esta diretriz, focou-se em uma dinâmica préavaliação.

Como em qualquer atividade de grupo, deve-se ter a cautela de se apropriar do perfil do grupo a se trabalhar. Em se tratando de profissionais técnicos focados em tecnologia da informação, deveriam ser escolhidas atividades de cunho prático, objetivo e ao mesmo tempo lúdicas, trabalhando as temáticas de forma mais leve, com foco no comportamento emitido e nos aspectos psicológicos envolvidos. A linguagem interpretativa das atividades também deveria ser adaptada para que se houvesse uma aproximação satisfatória com as facilitadoras e não se estabelecesse um distanciamento entre as partes.

Desta forma, foram organizados três grupos distintos, formados cada um por todos os integrantes das equipes de projetos selecionados para a avaliação. Cada sessão continha em média 10 (dez) componentes, envolvendo todos aqueles que participariam das sessões de avaliação. Escolheu-se para esta atividade um ambiente reservado, silencioso e amplo, permitindo a privacidade e o bem-estar dos participantes. Isto garantiu que os participantes se sentissem à vontade para exporem seus pensamentos, impressões e dúvidas.

O primeiro ponto que foi trabalhado referiu-se ao histórico da organização. Projetaram-se fotos que retratavam as etapas passadas pela empresa até o momento atual. Recuperaram-se imagens do antigo prédio da empresa, resgate do objetivo inicial da instituição (ser um centro de excelência em software), treinamentos ocorridos, as versões antigas do processo desenvolvido, eventos e imagens de atividades dos 10 meses anteriores. Complementando esta primeira abordagem foi apresentada uma breve contextualização sobre os objetivos genéricos da organização e qual a relação que existia com o momento da avaliação formal. A partir disto se obteve a real percepção de qual a representatividade da avaliação formal perante o contexto organizacional. Tendo em vista que o objetivo da empresa desde o princípio norteava o desejo de ser uma referência em qualidade de software, se percebeu que a avaliação formal era apenas uma das etapas para que se formalizasse a maturidade já alcançada pela empresa naquele momento.

Sugeriu-se a partir do tema trabalhado que o grupo lançasse palavras que, segundo a percepção dos mesmos, estivessem associadas ao tema "avaliação formal". O fato de não haver a obrigatoriedade de participação na dinâmica de Brainstorming facilitou o engajamento do grupo. Para correlacionar a forma de representação oral da temática (avaliação formal), disponibilizaram-se figuras que pudessem representar, naquele momento, de forma visual o tema entrevista de avaliação formal. O objetivo principal desta iniciativa foi acessar as diferentes percepções a cerca deste assunto.

Após este momento convocaram-se os gestores de projetos para conduzir uma dinâmica de identificação de riscos da avaliação oficial, do ponto de vista das equipes. $\mathrm{O}$ funcionamento desta atividade se deu da seguinte forma: lançou-se ao grupo o 
questionamento de quais riscos poderiam ter algum impacto durante a avaliação, e especificamente no momento das entrevistas individuais. Com estes dados identificados aleatoriamente pela equipe e registrados pelos gestores, foi proposto que, para cada risco, fossem estabelecidas estratégias para a minimizar o possível impacto dos mesmos.

Obtendo o consenso do grupo, a dinâmica foi concluída com a apresentação de um vídeo ilustrativo. O objetivo foi fazer um fechamento abordando temas como: o avanço tecnológico, a importância das relações humanas neste contexto e que o impacto de todas estas transformações não podem prejudicar o relacionamento entre as pessoas.

\subsection{Relato dos Resultados Encontrados}

Em cada atividade proposta e realizada percebeu-se algo convergente: o movimento e a sinergia do grupo transformaram simples atividades em iniciativas focadas em um objetivo em comum. Este tipo de movimento ocorre em chamados grupos operativos. Segundo Rivière (1980), grupo operativo consiste numa técnica de trabalho com grupos, cujo objetivo é promover, de forma econômica, um processo de aprendizagem. Aprender em grupo significa uma leitura crítica da realidade, uma apropriação ativa desta realidade. Tendo em vista este conceito, as equipes de projetos estariam imergindo na realidade que iriam vivenciar: a avaliação formal. A aprendizagem coletiva percebida entre os participantes foi observada e evidenciada pelas conclusões verbalizadas que, de opiniões individuais, passaram a ser consideradas por todo o grupo como um pensamento comum.

As ferramentas que foram utilizadas para trabalhar com as equipes de avaliação (grupos operativos) foram dinâmicas de grupo. Estas, conforme Altoé (1997), possibilitam vivências, que ao serem refletidas e partilhadas geram um aprendizado pessoal e grupal. Além disso, propiciam uma percepção do todo e das partes, o desenvolvimento da consciência crítica, a tomada de decisão de forma consciente e crítica e o compartilhamento coletivo de diferentes aprendizados, através de metáforas. O estudo do público que iria ser trabalhado foi fundamental, pois através disso, foram selecionadas tarefas coerentes e assertivas com o momento e estilo das equipes participantes, garantindo o engajamento dos mesmos e aumentando a probabilidade de se atingir os objetivos mapeados. Equipes técnicas têm por característica serem objetivas, racionais e pouco participativas em atividades lúdicas. Por esta razão teve-se o cuidado de selecionar dinâmicas focadas, claras e objetivas, porém não perdendo o caráter lúdico.

O movimento de partir-se de algo genérico e contextualizado com a realidade organizacional, no qual as equipes estavam inseridas (objetivos gerais da organização, a razão pela qual o nível de maturidade seria importante para a empresa e para os profissionais envolvidos, número de ações realizadas para este fim, etc) fez com que fosse agregado ao conceito de avaliação formal todo um contexto que estava mobilizado para um objetivo: o de a Tlantic ser considerada uma empresa de referência em desenvolvimento de software. Isto propiciou a mudança da percepção que muitas vezes o grupo manifestava de que caso não tivessem sucesso na entrevista de avaliação seriam os responsáveis pelo fracasso do projeto e de toda a empresa de que a avaliação formal nada mais era do que uma etapa em busca da excelência em qualidade.

Propondo a discussão sobre uma temática mais genérica, sentiu-se a necessidade de se trabalhar comportamentalmente algo que se remetia a prática propriamente dita: a entrevista de avaliação. Como exposto anteriormente usaram-se figuras para que fossem 
projetadas percepções individuais a cerca desta situação. Com isto, em nível de resultado, pôde-se acessar aquilo que era percebido por cada um como representativo do momento de contato direto com a comissão avaliadora. Expressando-se livremente a respeito de suas idéias cada membro do grupo pôde visualizar o quanto sua percepção se distinguia da do outro. Pode-se observar que em nenhum momento as figuras se repetiram, ou seja, as percepções entre os componentes do grupo eram bem diferentes. Exemplificando essa diversidade podemos citar figuras as quais foram atribuídos os seguintes significados: desafio (representado pela figura de uma montanha), conquista (figura de um pódio), pressão e foco da atenção (figura de um olho e uma lupa). Assim, juntamente com a técnica de levantamento de riscos e estratégias para minimização dos mesmos foi possível desmistificar de certa forma o momento tão temido e ansiogênico da entrevista e, com isso, reduzir de forma gradativa a ansiedade antecipatória. Como estratégias levantadas na dinâmica e utilizadas posteriormente podemos destacar a técnica de relaxamento, que, segundo citações dos envolvidos, foi de grande valia para a diminuição dos sintomas físicos oriundos da ansiedade situacional.

Para Scott \& Beck (1994), a ansiedade é o sentimento que acompanha um sentido geral de perigo, ela nos adverte de que há algo há ser temido no futuro. Ao mesmo tempo, a ansiedade alimenta o planejamento de ações, buscando saídas, alternativas e ensaiando ações de enfrentamento ou fuga do perigo. Este movimento pôde ser percebido na busca de estratégias para que se fossem reduzidos os aspectos que provocavam certo receio frente à situação desconhecida de "avaliação" que os participantes estariam expostos. A avaliação da ansiedade depende de sua proporcionalidade ao perigo que é apresentado e também em que grau provoca a paralisação da pessoa frente ao perigo. A "boa ansiedade" é proporcional às dificuldades, e promove o enfrentamento saudável. A "má ansiedade" é desproporcional à dificuldade tornando a pessoa improdutiva diante das dificuldades. Como reações presentes nas equipes de projeto podem-se destacar as seguintes: agitação, rubor, tremores, sensações de "branco", falta de confiança na própria performance, entre outras.

A técnica de dessensibilização sistemática estudada na psicologia clínica foi de certa forma praticada com as equipes de projetos. Freeman e Dattilo (1995) conceituam esta como sendo uma técnica que visa diminuir a ansiedade frente ao objeto ou situação temida. Para alcançar este objetivo é necessário que o sujeito desenvolva estratégias de enfrentamento daquilo que teme, seja falando sobre a situação, fazendo simulações, aproximando-se gradativamente daquilo que se esquiva, entre outros. Transpondo para a realidade das equipes de projetos foi-se trabalhado como deveriam ser manejados os comportamentos que poderiam trazer algum risco comprometendo o resultado da avaliação. Em suma, quanto mais foi falado sobre aquilo que as afligia, menos "monstruosa" passou a se tornar a situação.

\section{Lições Apreendidas}

As atividades propostas e realizadas com as equipes de projeto permitiram uma avaliação bastante interessante do momento pré-avaliação oficial. Como a atividade foi realizada duas semanas antes da avaliação, os resultados encontrados permitiram que a equipe responsável pela gestão do projeto de melhoria dentro da organização direcionasse alguns esforços no sentido de trabalhar dificuldades ainda existentes. 
Desta forma, identificaram-se também algumas lições aprendidas das atividades realizadas. Estas lições são descritas a seguir:

Lição 1: Importância de se desenvolver aspectos comportamentais em profissionais técnicos

Acredita-se que a atividade conduzida contribuiu para que os integrantes das equipes dos cinco projetos envolvidos no contexto da avaliação oficial pudessem compartilhar preocupações e sentimentos que não foram compartilhados em momentos anteriores, ou que foram feitos de uma maneira informal ou ainda por demanda de alguns profissionais apenas, fora de um contexto de grupo.

Lição 2: Estar atento sensivelmente à demanda implícita frente a um processo de tamanha mobilização organizacional e pessoal

O programa de melhoria de processos de software mobilizou os profissionais da organização como um todo, envolvendo todos os níveis hierárquicos. Mas a percepção da necessidade de uma atividade como a que foi relatada só foi possível devido à insistência de focar a preparação das equipes não apenas tecnicamente, mas também psicologicamente (o que não foi facilmente percebido).

Lição 3: Buscar a complementaridade das áreas em prol da qualidade de vida no trabalho e do alcance das metas organizacionais e pessoais

$\mathrm{O}$ envolvimento da área de recursos humanos em atividades destacadas do projeto de melhoria visando o CMMI nível 2 foi essencial para que os profissionais da organização se sentissem bem no ambiente de trabalho enquanto eram desenvolvidos esforços para atingir as metas definidas pela organização. Ainda, foi possível complementar a formação dos profissionais e possibilitar a identificação de comportamentos antes não observados nas equipes dos projetos.

Lição 4: Importância do conhecimento da equipe que se irá trabalhar, buscando uma aproximação e uma relação de confiança

Um outro fator importante para o sucesso do projeto foi à identificação de oportunidades de aquisição de confiança e de um maior conhecimento envolvendo as equipes de projeto, a equipe de qualidade da organização e a desmistificação da figura da equipe de avaliação como algo negativo.

Lição 5: Comunicação clara dos objetivos organizacionais e de todos os passos para 0 alcance destas metas

A última lição identificada diz respeito à importância da apresentação do andamento do projeto periodicamente para todos, comunicando claramente onde a organização estava, onde pretendia chegar, e o que precisava fazer para isto.

\section{Conclusão}

Programas de melhoria de processo de software tradicionalmente geram diversos esforços que devem ser conduzidos de uma forma planejada e coerente pela organização como um todo, representada muitas vezes por uma equipe de qualidade (ou SEPG). Muitas vezes, estes esforços estão focados no desenvolvimento, treinamento e institucionalização de processos de software, preparando as equipes de projetos para responder tecnicamente às necessidades propostas. Mas muitas vezes, uma equipe bem preparada tecnicamente ao 
longo de um projeto como este pode não responder como o esperado no momento em que é necessária apenas a comprovação prática do que tem sido feito diariamente.

Desta forma, este relato compartilha uma experiência onde foram observadas algumas demandas complementares de preparação de equipes de projetos em atividades de avaliação (no caso uma avaliação oficial). Geralmente as avaliações compreendem diagnosticar a execução das práticas de desenvolvimento de software à luz de modelos de qualidade reconhecidos. E após a análise dos resultados, das lições identificadas e do alcance do objetivo do projeto (nível dois no modelo CMMI), entende-se que a atividade realizada foi determinante para complementar a preparação das equipes dos projetos para a avaliação, sob a ótica de aspectos não técnicos. Entende-se ainda que uma contribuição deste relato é o fato de que as atividades propostas e avaliadas podem ser aplicadas em outros projetos de melhoria, em outras organizações e com outros modelos de qualidade.

Por fim, as lições identificadas apontam para algumas características que já fazem parte de programas de melhoria, tais como a comunicação clara dos objetivos e a importância do conhecimento da equipe que se irá trabalhar. Por outro lado, muitas vezes não é claro para uma organização que implementa programas de qualidade a importância de se desenvolver aspectos comportamentais em profissionais técnicos, ou ainda a demanda implícita existente em um projeto que entre suas características a mobilização organizacional. Por fim, acredita-se que uma lição destacada deste relato foi a busca pela complementaridade das áreas em prol da qualidade de vida no trabalho e do alcance das metas organizacionais, o que só foi possível devido ao envolvimento da área de recursos humanos da empresa em atividades de extrema importância para o projeto.

\section{Referências}

AGNOL, S., HERBERT, J. S. Utilização do TSP para a Gerência de Equipes Nível 2 do CMMI. In: SIMPROS 2004 - VI Simpósio Internacional de Melhoria de Processos de Software, São Paulo, SP, Brasil, 107-118.

ALTOÉ, A. Recriando experiências: Técnicas e dinâmicas para grupos. São Paulo: Paulus Ed, 1997.

BARTIÉ, Alexandre. Garantia da qualidade de software: adquirindo maturidade organizacional. Rio de Janeiro, Elsevier, 2002.

FREEMAN, A e DATTILO, F. M. Estratégias cognitivo comportamentais para intervenção em crise. São Paulo: Editorial Psy, 1995.

JALOTE, P. CMM in practice: processes for executing software projects at Infosys, Addison Wesley Longman, 1999.

PICHON-RIVIÈRE, E. El proceso grupal. Buenos Aires: Ed. Nueva Visión, 1980.

SCOOT, J., Williams, J. M. \& BECK, A. T. Terapia Cognitiva na Prática Clínica. Um Manual Prático. Porto Alegre, Artes Médicas, 1994.

SOMMERVILLE, Ian, Engenharia de software, $6^{\mathbf{a}}$ ed., Addison Wesley, 2003.

\footnotetext{
${ }^{1}$ Este trabalho foi realizado no âmbito do Projeto Qualidade, realizado na Tlantic SI, em parceria com a DBServer, a Faculdade de Informática da PUCRS e apoio do ESICenter Unisinos.
} 